\title{
Characterization of adipocyte differentiation from human mesenchymal stem cells in bone marrow
}

\author{
Shu-Wen Qian' 1 Xi Li1,2, You-You Zhang ${ }^{1}$, Hai-Yan Huang1,2, Yuan Liu' 1 , Xia Sun ${ }^{1}$ and Qi-Qun Tang*1,2
}

\begin{abstract}
Background: Adipocyte hyperplasia is associated with obesity and arises due to adipogenic differentiation of resident
multipotent stem cells in the vascular stroma of adipose tissue and remote stem cells of other organs. The mechanistic
characterization of adipocyte differentiation has been researched in murine pre-adipocyte models (i.e. 3T3-L1 and 3T3-
F442A), revealing that growth-arrest pre-adipocytes undergo mitotic clonal expansion and that regulation of the
differentiation process relies on the sequential expression of three key transcription factors (C/EBP?, C/EBP? and PPAR?).
However, the mechanisms underlying adipocyte differentiation from multipotent stem cells, particularly human
mesenchymal stem cells (hBMSCs), remain poorly understood. This study investigated cell cycle regulation and the
roles of C/EBP?, C/EBP? and PPAR? during adipocyte differentiation from hBMSCs.
Results: Utilising a BrdU incorporation assay and manual cell counting it was demonstrated that induction of
adipocyte differentiation in culture resulted in 3T3-L1 pre-adipocytes but not hBMSCS undergoing mitotic clonal
expansion. Knock-down and over-expression assays revealed that C/EBP?, C/EBP? and PPAR? were required for
adipocyte differentiation from hBMSCs. C/EBP? and C/EBP? individually induced adipocyte differentiation in the
presence of inducers; PPAR? alone initiated adipocyte differentiation but the cells failed to differentiate fully. Therefore,
the roles of these transcription factors during human adipocyte differentiation are different from their respective roles
in mouse.
Conclusions: The characteristics of hBMSCS during adipogenic differentiation are different from those of murine cells.
These findings could be important in elucidating the mechanisms underlying human obesity further.
\end{abstract}
\section{Background}

Increased adipose tissue mass associated with obesity is due to the increased number and size of adipocytes [1,2]. Adipocyte differentiation from mesenchymal stem cells plays an important role in the hyperplasia of adult adipose tissue. A population of cells resident in the vascular stroma of adipose tissue can differentiate into adipocytes in vitro and in vivo [3]. Recent studies indicate that pericytes in blood vessel walls have adipogenic potential, express mesenchymal stem cell (MSC) markers and are multipotent [4]. In addition to resident stem cells, nonresident stem cells can serve as a source of adipocyte precursors; bone marrow MSCs can be recruited to adipose tissue and generate new adipocytes in response to treat-

\footnotetext{
* Correspondence: qqtang@shmu.edu.cn

${ }^{1}$ Institute of Stem Cell Research and Regenerative Medicine, Institutes of Biomedical Sciences, Fudan University, Shanghai 200032, PR China Full list of author information is available at the end of the article
}

ment with thiazolidinediones (TZDs) or high fat stimulation [5].

The characteristics and molecular mechanism underlying adipocyte differentiation have been extensively investigated in the murine pre-adipocyte cell lines 3T3-L1 and 3T3-F442A [6,7]. Growth-arrested pre-adipocytes have been shown to re-enter the cell cycle synchronously and undergo mitotic clonal expansion in response to MDI (M: methyl-isobutyl-xanthine, D: dexamethasone, I: insulin) treatment, before exiting the cell cycle and terminally differentiating [8]. The transcription factors C/EBP? (CCAAT/enhancer binding protein ?), C/EBP? (CCAAT/ enhancer binding protein ?) and PPAR? (peroxisome proliferator-activated receptor ?) act sequentially during 3T3-L1 pre-adipocyte differentiation [9]. C/EBP? is induced immediately after exposure to the differentiation cocktail, resulting in phosphorylation and activation $[10,11]$, and it transactivates the expression of C/EBP? and PPAR? [12]. C/EBP? and PPAR?, together or in isola- 
tion, can initiate differentiation without inducers [13-15]. $\mathrm{C} / \mathrm{EPB}$ ? is believed to be relevant to the acquisition of insulin sensitivity [16].

MSCs have been isolated and induced to differentiate into adipocytes in a variety of organs [17-22]. However, the differentiation procedure and the roles of adiposerelated genes in that procedure have not been characterized completely owing to the heterogeneity, low proliferation ability and ineffective ectopic gene transfection of hBMSCs $[23,24]$. Human primary cells are of great interest because of their biological and therapeutic potential, therefore this study extends the research carried out in murine 3T3-L1 cells to hBMSCs from bone marrow.

\section{Results}

\section{Isolation and adipogenic differentiation of hBMSCs}

Isolated $\mathrm{hBMSCs}$ presented with a typical spindle-shape phenotype (Figure 1A), and cells from passages 3-5 were used for the following studies. In addition to fetal bovine serum (FBS), methyl-isobutyl-xanthine, dexamethasone and insulin (MDI) used to induce 3T3-L1 adipocyte differentiation, indomethacin (Indo), a PPAR? agonist [25], was added to the culture medium (MDI+Indo) to induce adipocyte differentiation from hBMSCs [26]. Each cycle of MDI+Indo threatment only induced a portion of hBMSCs to go into adipocyte differentiation, and about $60 \%$ $70 \%$ hBMSCs differentiated into adipocytes after three cycles of MDI+Indo induction as indicated by oil red $\mathrm{O}$ staining (Figure 1B). Consistent with the morphological changes, the expression of the adipose-specific gene FABP4 (422/aP2 in mouse) was significantly induced throughout differentiation as determined by Western Blotting (Figure 1C).

\section{Cell cycle alteration during adipocyte differentiation from hBMSCs}

HBMSCs proliferated slowly, approximately $<10 \%$ of cells were actively dividing revealed by DNA content with flow cytometry (Fig.2A). About 90\% of the cells in G0/G1 phase were at the dividing stage, and approximately $95 \%$ at the post-confluence stage (Figure 2B). Contact inhibition was not apparent, as observed that if plated at a density of 5000 cells $/ \mathrm{cm}^{2}$ and cultured for five weeks, the cells locally grew into multi-layers (Figure 2C).

Cell cycle regulation is an important event in adipocyte differentiation of mouse 3T3-L1 pre-adipocytes $[8,11]$. Growth-arrested 3T3-L1 pre-adipocytes synchronously re-enter the cell cycle upon MDI induction and undergo two rounds of division before expression of adipocytespecific genes and presenting with the mature adipocyte phenotype. In order to investigate whether hBMSCs undergo division during adipocyte differentiation, the number of cells was counted (Figure 3B). The cell number marginally increased ( 1.24 fold) in the control group after a 21-day culture (Figure 3A). There was an increase in the cell number ( 1.17 fold) in differentiation cultures but less than that in the control, and as the number of differentiated cells increased after repeated inductions, the rate of increase of cell numbers declined. These results suggest that the proliferation of undifferentiated cells contributed to the increase in cell numbers.

BrdU incorporation assays were performed to investigate whether DNA synthesis occurs during adipocyte differentiation from hBMSCs. We found that differentiated hBMSCs were BrdU negative, while differentiated 3T3L1 cells were BrdU positive (Figure 3C). Confocal microscopy verified the positional relationship between nuclei (as indicated by BrdU incorporation into DNA) and cells with lipid droplets in the cytoplasm (Figure 3D, 3E).

These results demonstrate that hBMSCs did not undergo mitotic clonal expansion during adipogenic differentiation under culture conditions.

\section{Role of C/EBP? in adipocyte differentiation of hBMSCs}

In order to define the role of C/EBP? in adipocyte differentiation of hBMSCs, the expression profile was determined. Expression of C/EBP? in hBMSCs could be detected at the start of induction by real-time PCR; the expression level did not change significantly during the early stages of induction (Figure 4A) but declined after 14 days when most of the cells had differentiated. Regarding the expression difference between 3T3-L1 and hBMSCs, $\mathrm{C} / \mathrm{EBP}$ ? expression was knocked down by siRNA to determine whether C/EBP? is essential during adipocyte differentiation from hBMSCs; and knocked-down expression of C/EBP? was confirmed by real-time PCR (Figure 4C). HBMSCs failed to differentiate into adipocytes after C/EBP? was knocked down (Figure 4B). $\mathrm{C} / \mathrm{EBP}$ ? was over-expressed in $\mathrm{hBMSCs}$ using an adenovirus expression system (Figure 4D) to investigate its function during differentiation. Control cells expressing Lac Z didn't differentiate, while expression of exogenous C/EBP? alone induced adipogenesis (Figure $4 \mathrm{E}$ ), and some cells presented with small intracellular fat droplets that could not be adequately stained using oil red $\mathrm{O}$. However, FABP4 expression was detected by western blotting (Figure $4 \mathrm{~F}$ ) and was significantly up-regulated by the addition of inducers, the highest levels of expression being evident when indomethacin (PPAR? agonist) was included (Figure 4E, 4F).

\section{Role of C/EBP? in adipocyte differentiation from hBMSCs}

Expression of $\mathrm{C} / \mathrm{EBP}$ ? increased one day after induction, reached a maximum level after three days and decreased by day 14 when adipocyte differentiation had occurred (Figure 5A). As Figure 5B demonstrates, knocked-down expression of C/EBP? (Figure 5C) with an adenovirus carrying $C / E B P$ ? shRNA impaired the differentiation of 
A

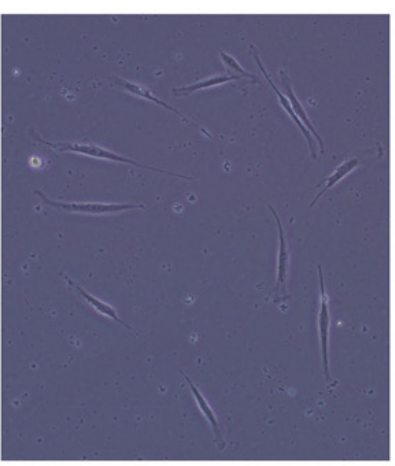

3 days

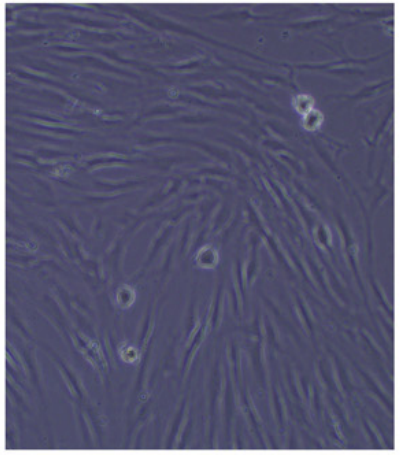

12 days

B

\section{MDI+Indo}

\section{Control

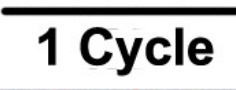 \\ 2 Cycles 3 Cycles}
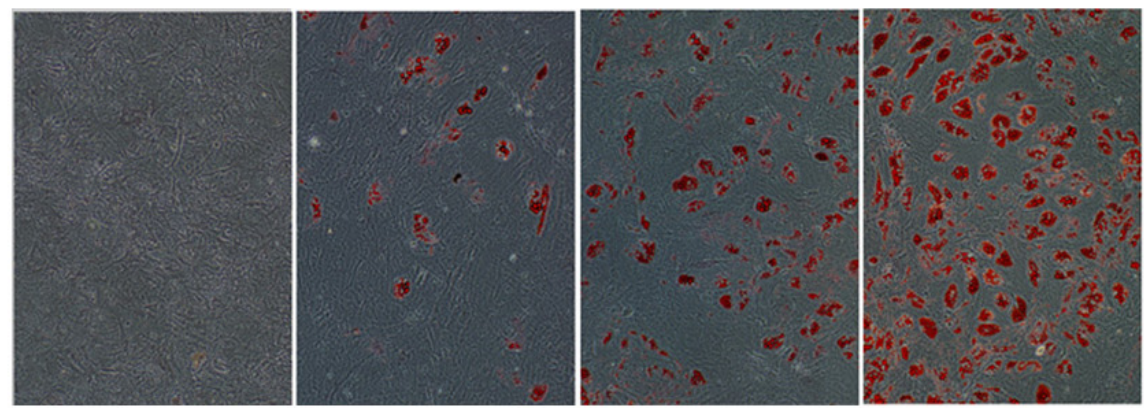

C
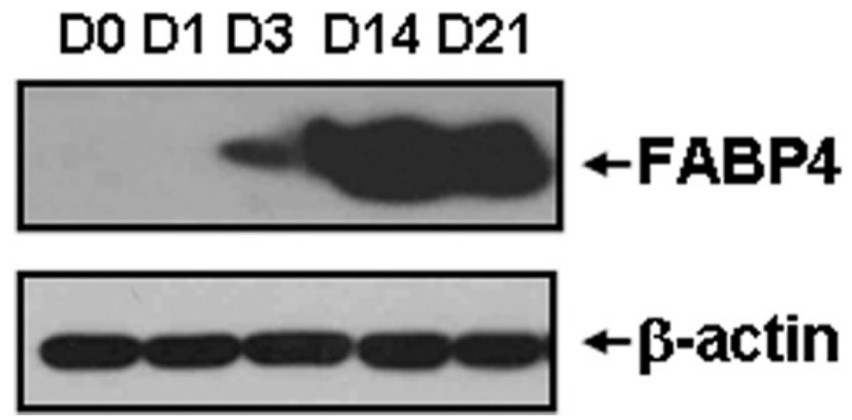

Figure 1 Isolation and adipogenic differentiation of hBMSCs. (A) The morphology of adherent hBMSCs three and 12 days after plating (magnification 100X). (B) HBMSC of P5 were cultured for one week after confluence and induced to differentiate with MDI+Indo (M: methyl-isobutyl-xanthine; D: dexamethasone; I: insulin; Indo: indomethacin) treatment for one, two or three cycles (1 cycle of treatment: MDI+Indo for three days followed by insulin for one day). The accumulation of cytoplasmic triglyceride was detected by Oil Red O staining on day 21 and visualized under a microscope (magnification 100x). (C) FABP4 expression was examined by Western Blotting at the indicated days after differentiation with repeated MDI+Indo treatment (three times). 


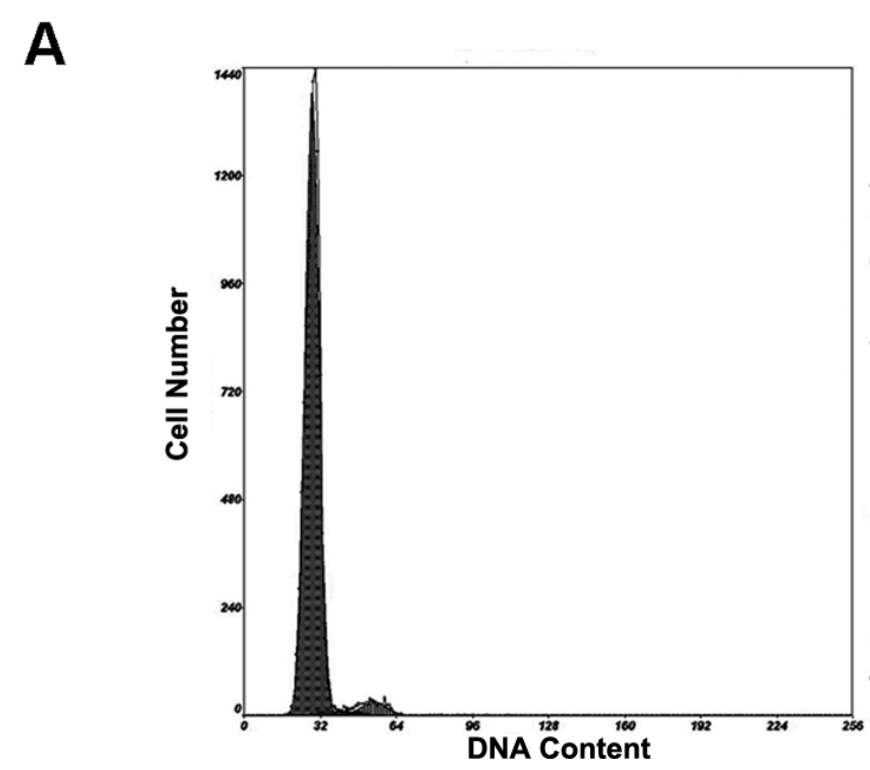

B
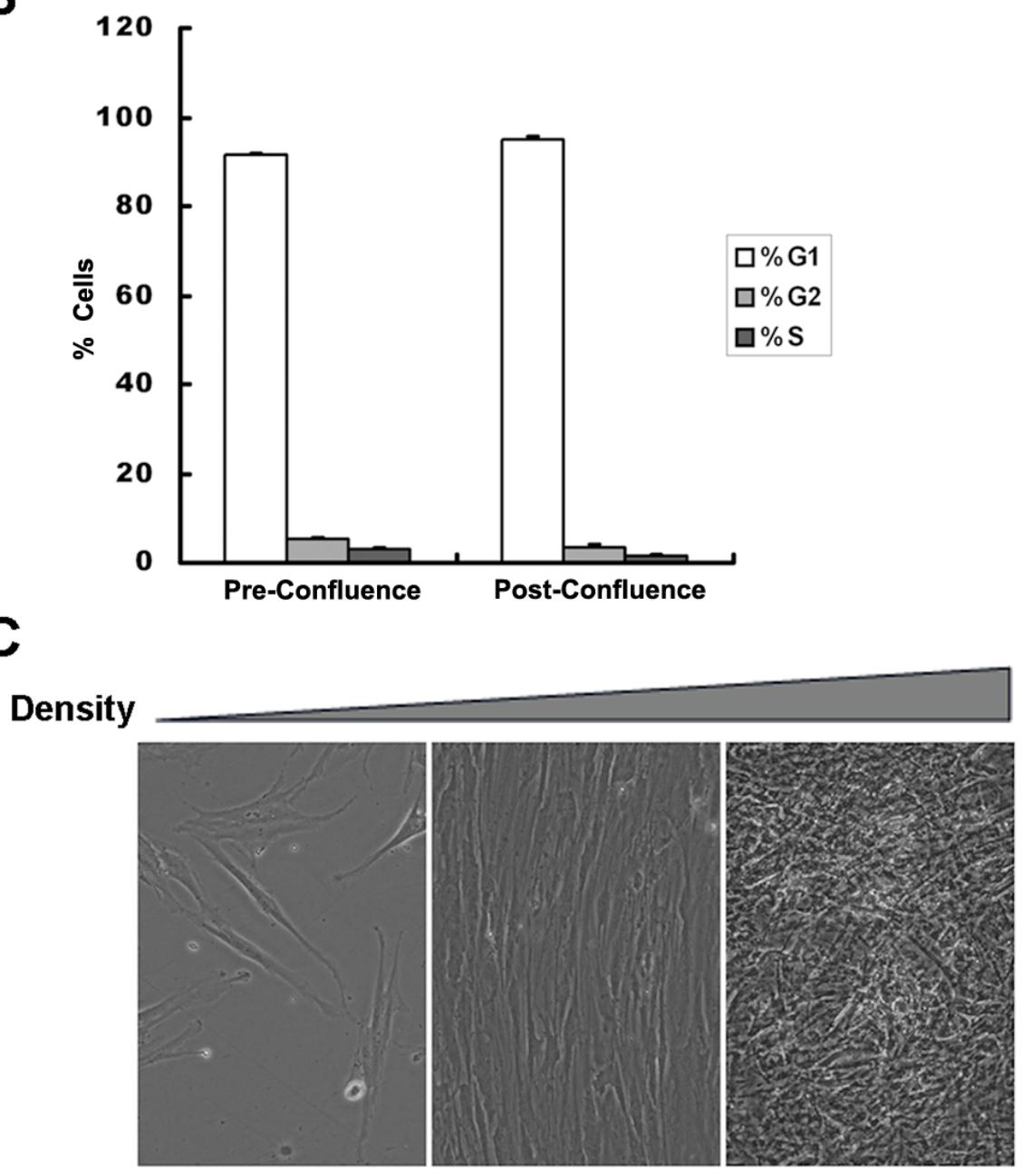

Figure 2 Growth characteristic of hBMSCs. (A) Confluent hBMSCs were trypsinized, fixed and stained with PI. DNA content in cells was examined by flow cytometry. (B) Pre-confluent (density $\sim 80 \%$ ) and post-confluent (one week after cells reach confluence) hBMSCs from three separate experiments at different cell cycle stages revealed by flow cytometry were quantified. (C) Morphology of hBMSCs at different densities (plated at 5000/(cm² and cultured for one day, one week and five weeks). 


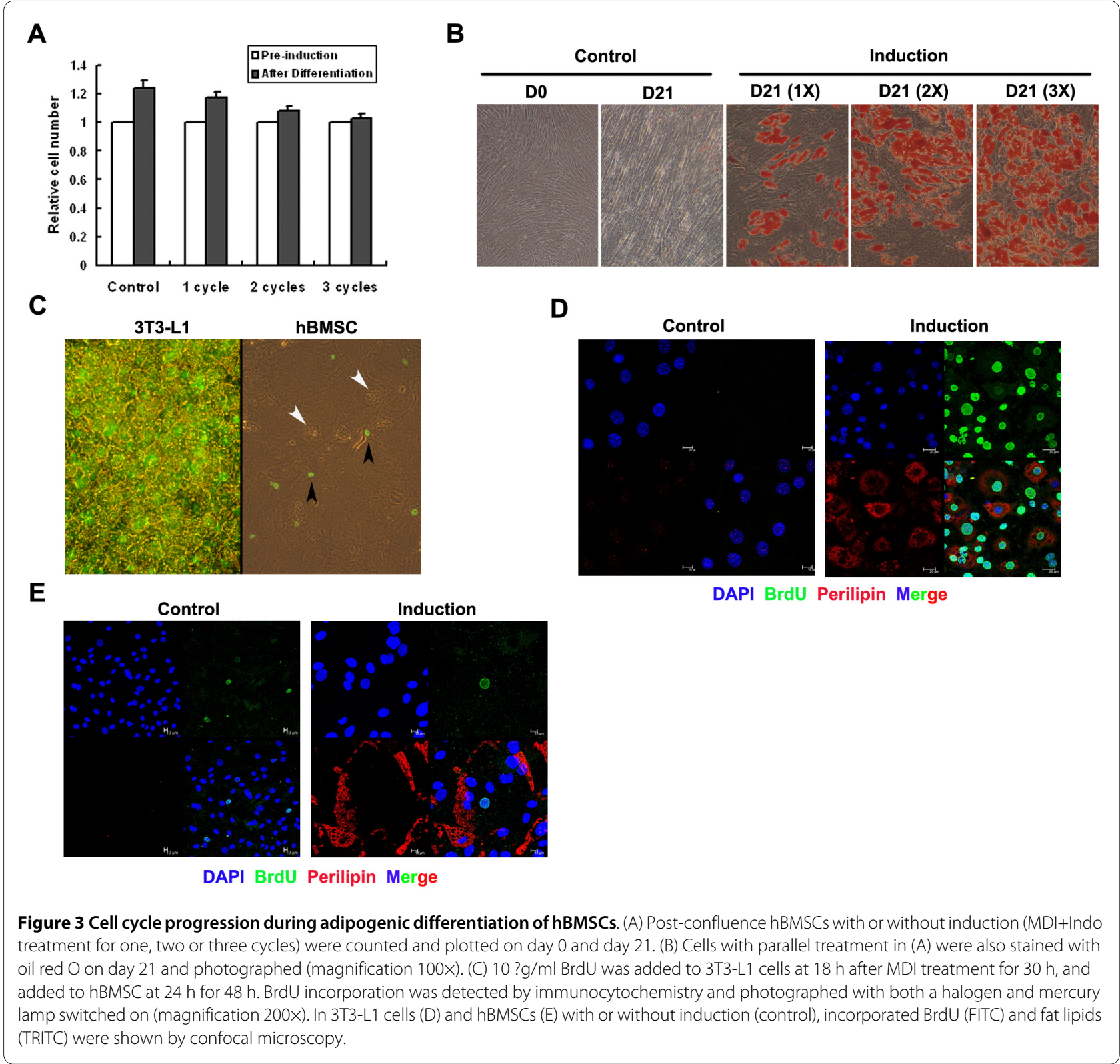

hBMSCs, while over-expression of C/EBP? (Figure 5D) in hBMSCs did not induce adipocyte differentiation. However, $\mathrm{C} / \mathrm{EBP}$ ? together with indomethacin or MDI induced a small proportion of the cells to differentiate, and when both indomethatin and MDI were added with $\mathrm{C} / \mathrm{EBP}$ ?, the number of differentiated adipocytes increased as demonstrated by oil red $\mathrm{O}$ staining (Figure $5 \mathrm{E}$ ) and Western Blotting of FABP4 expression (Figure $5 \mathrm{~F})$.

\section{Role of PPAR? in adipocyte differentiation from hBMSCs}

The induction of PPAR? expression was similar to that of C/EBP? (Figure 6A, Figure 5A). Knock-down of PPAR? expression in hBMSCs (Figure 6C) prevented adipocyte differentiation (Figure 6B), while over-expression of
PPAR? (Figure 6D) induced adipogenic differentiation (Figure 6E), resulting in fat droplet accumulation in the vast majority of cells. Addition of an exogenous PPAR? agonist (indomethacin) enhanced the function of PPAR? as determined by oil red $\mathrm{O}$ staining (Figure 6E) and FABP4 expression (Figure 6F). Fat droplets appeared three days after adenoviral infection but were smaller than those induced by MDI+Indo (Figure 6G). The expression ratio of GLUT4 to FABP4 in adipocytes induced by PPAR? over-expression was lower than that in cells induced by three cycles of MDI+Indo (Figure $6 \mathrm{H}$ ). 


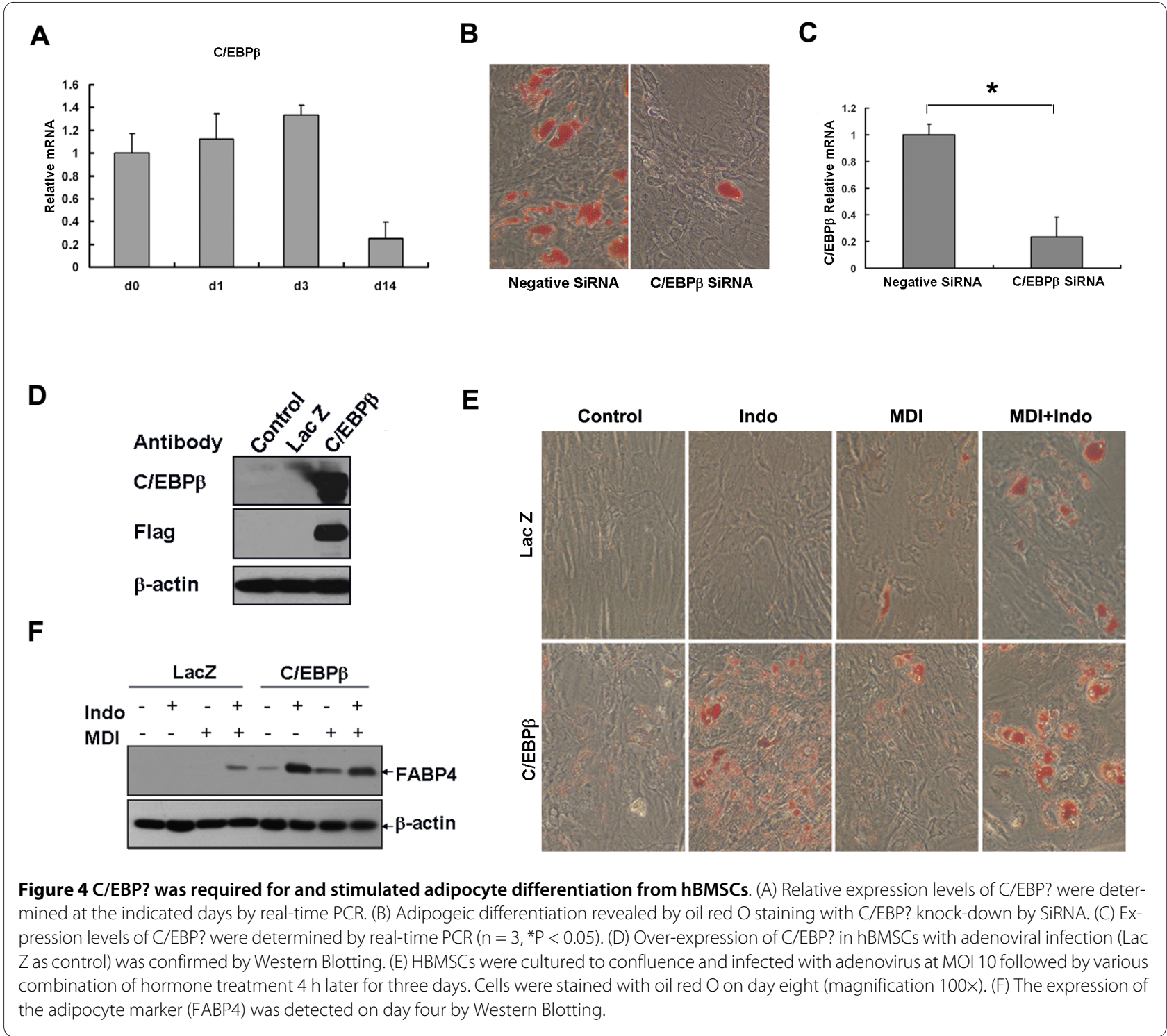

\section{Discussion}

HBMSCs are more difficult to handle than mouse stem cell lines but their importance and therapeutic potential necessitate their use in research of the type outlined herein. The previous studies are focused on the mouse stem cell lines but the regulation of them could be different in some aspects, and results of murine cells would be less convincing in interpreting the onset of human disease. On the other hand, adipocytes differentiated from HBMSCs would be of better immuno-compatibility in autograft for plastic purpose. So, in this study, a comprehensive analysis of adipocyte differentiation from multipotent human stem cells was carried out.

HBMSCs were isolated from bone marrow and induced to differentiate into adipocytes under culture conditions. The PPAR? agonist, indomethacin, was added as well as the conventional inducers used in adipocyte differentia- tion protocols for murine pre-adipocytes. HBMSCs behaved differently from 3T3-L1 pre-adipocytes, with only a small number of cells differentiating into adipocytes after one cycle of treatment; approximately $60 \% \sim 70 \%$ of hBMSCs differentiated into adipocytes after three cycles of treatment (Figure 1B). A long G0 phase and a lack of contact inhibition (Figure 2C) meant that hBMSCs did not synchronize at the time when differentiation was initiated (Figure 2B). Growth arrest is a prerequisite for adipocyte differentiation [27], so it was concluded that only a minority of hBMSCs were growth arrested when differentiation was induced. MCE (mitotic clonal expansion) is an essential event associated with adipocyte differentiation from mouse pre-adipocyte cell lines $[8,11]$. However, it is not known whether MCE is required for adipocyte differentiation from all cell types. We have previously demonstrated that 
A

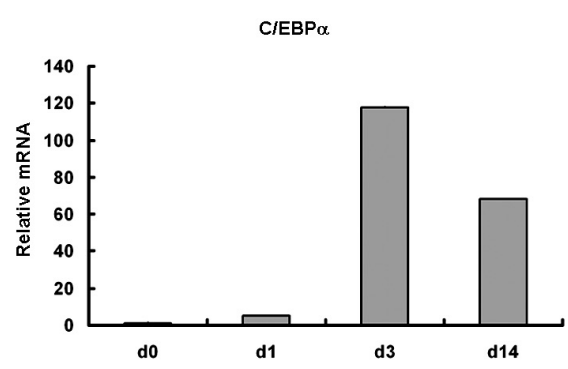

D
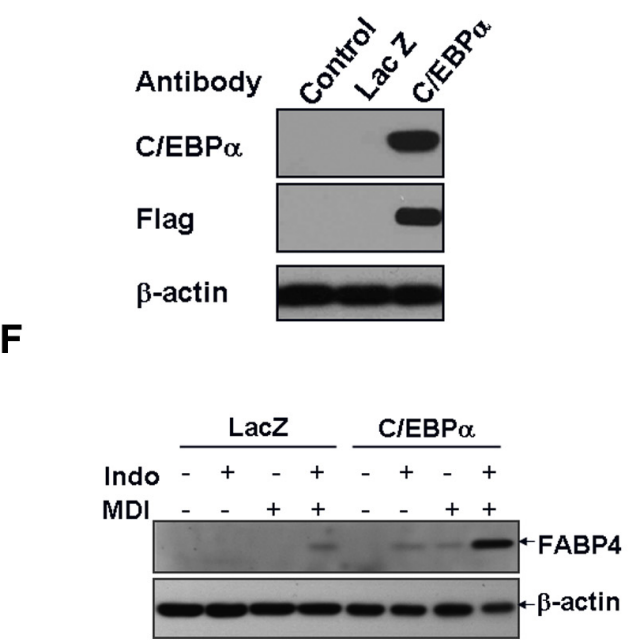

B

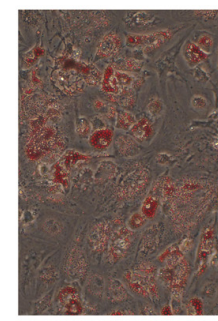

Lac Z ShRNA

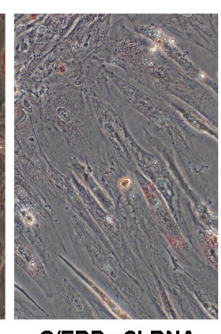

C/EBP $\alpha$ ShRNA
C

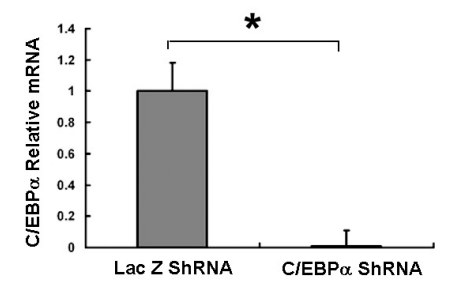

E

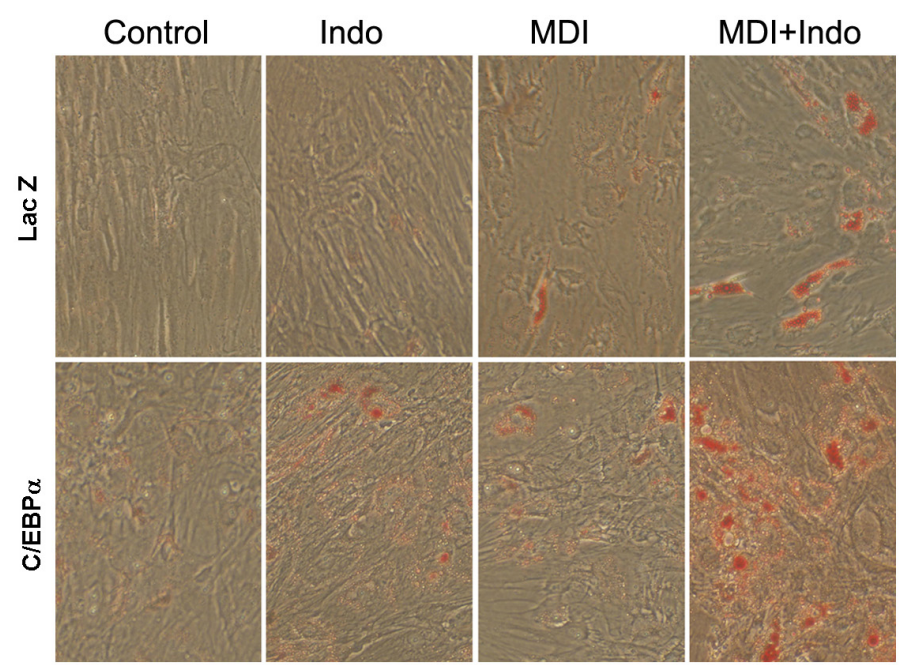

Figure $\mathbf{5}$ C/EBP? was required for and stimulated adipocyte differentiation from hBMSCs. (A) Relative expression levels of C/EBP? were determined at the indicated days by real-time PCR. (B) Adipocyte differentiation revealed by oil red O staining with C/EBP? knock-down by adenovirus expressing shRNA. (C) C/EBP? knock-down was confirmed by real-time PCR ( $n=3,{ }^{*} P<0.05$ ). (D) C/EBP? over-expression in hBMSCs using adenovirus (Lac Z as control) was shown by Western Blotting. (E) HBMSCs were cultured to confluence and infected with adenovirus at MOI 10 followed by various combinations of hormone treatment $4 \mathrm{~h}$ later for three days. Cells were stained with oil red $\mathrm{O}$ on day eight (magnification 100x). ( $\mathrm{F}$ ) The expression of the adipocyte marker (FABP4) was detected on day four by Western Blotting.

committed C3H10T1/2 cells treated with BMP4 divide when induced to differentiate [28], and primary cultures of mouse embryonic fibroblasts (MEF) undergo MCE when differentiating into adipocytes [29]. In this study, hBMSCs from bone marrow did not undergo division during differentiation (Figure 3), which is in agreement with other reports showing that adipose precursor cells prepared from human adipose tissue (hADSCs) did not divide during differentiation under culture conditions [30]. The authors argued that hADSCs had completed division before being isolated; however, hADSCs are multipotent and can differentiate into other cell lineages including adipocytes ex vivo [31,32]. HADSCs could behave similarly to hBMSCs from bone marrow under culture conditions and remain uncommitted. The diversity of cell cycle alterations during adipocyte differentiation could be species-specific.
Murine proteins and comparable human proteins can function differently in the same context. In this study, C/ EBP? expression in hBMSCs did not alter significantly during the early stages of induction whereas expression was up-regulated immediately following induction and declined after two days in 3T3-L1 pre-adipocytes [33]. The decline of $\mathrm{C} / \mathrm{EBP}$ ? at 14 day might result from most of cells being terminal differentiated. However, C/EBP? was required for adipocyte differentiation in hBMSCs as its knock-down expression impaired differentiation (Figure $4 \mathrm{~B}, 4 \mathrm{C})$. C/EBP? has important roles in mitosis and terminal adipocyte differentiation $[34,35]$, but mitosis did not occur during differentiation of hBMSCs (Figure 3) and that could possibly explain the lack of differential expression of $C / E B P$ ? upon induction. It is likely that the role of $\mathrm{C} / \mathrm{EBP}$ ? during adipocyte differentiation from $\mathrm{hBMSCs}$ relates to its modification and not its expression 
A

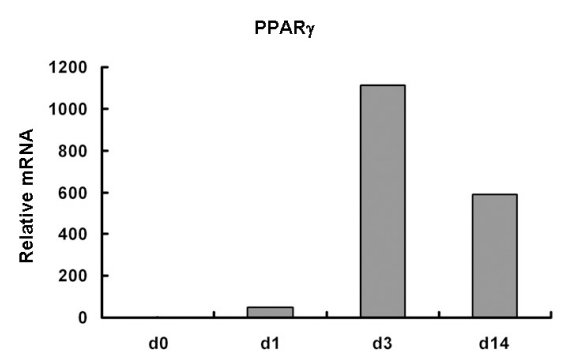

D

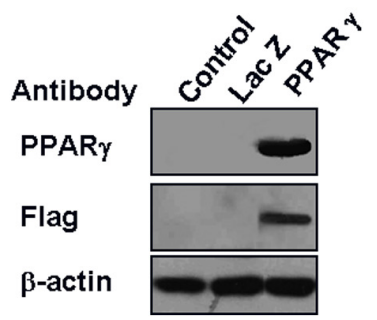

G

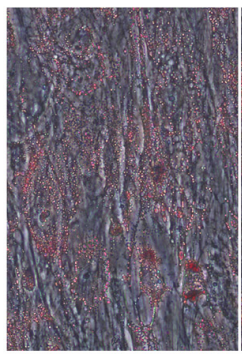

PPAR $\gamma$

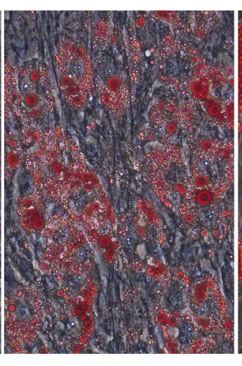

PPAR $\gamma+$ Indo
B

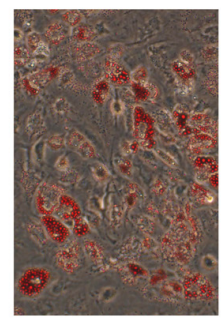

Lac Z ShRNA

E

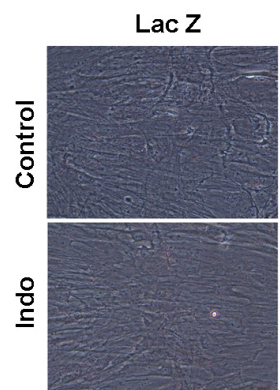

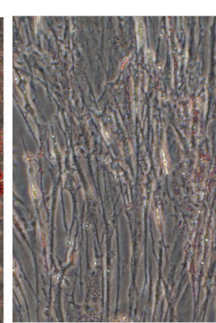

PPARy ShRNA
C

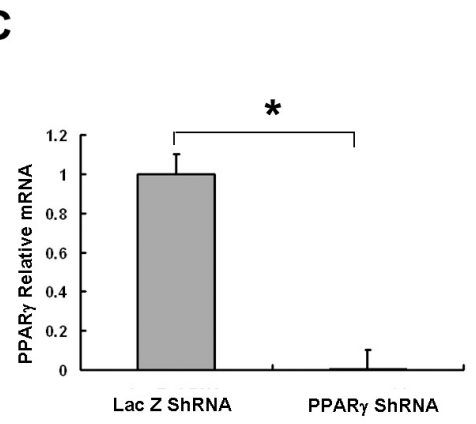

$\mathbf{F}$

PPAR $\gamma$

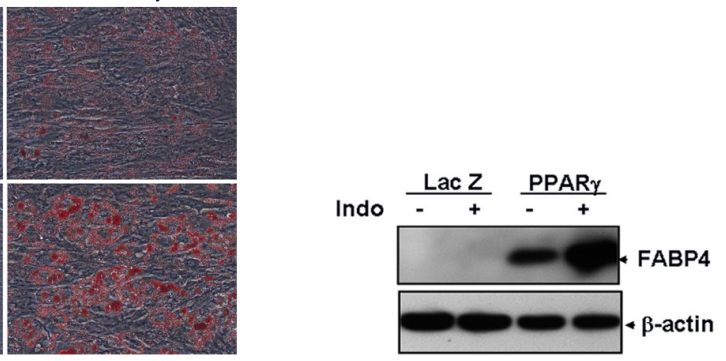

H

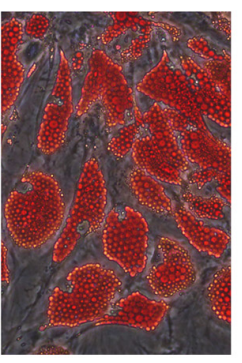

MDI+Indo

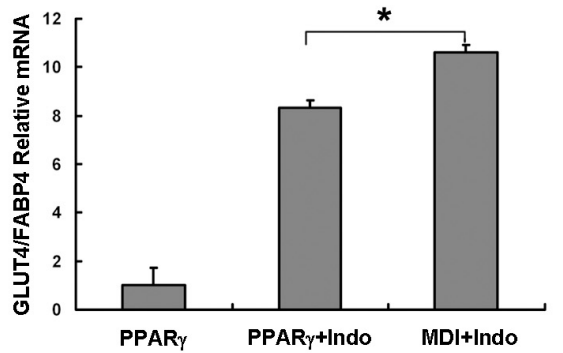

Figure 6 PPAR? was sufficient to initiate adipocyte differentiation from hBMSCs, but could not induce fully developed adipocytes. (A) Relative expression levels of PPAR? were determined at the indicated days by real-time PCR. (B) Adipogeic differentiation revealed by oil red $O$ staining with PPAR? knock-down by adenovirus expressing shRNA. (C) PPAR? knock-down was verified by real-time PCR $\left(n=3,{ }^{*} P<0.05\right)$. (D) PPAR? over-expression in hMBSCs with adenovirus (Lac Z as control) was shown by Western Blotting. (E) HBMSCs were cultured to confluence and infected with adenovirus at $\mathrm{MOI} 10$ alone or in combination with indomethacin. Lipid droplets indicated by oil red O staining on day 14 (magnification 100X). (F) The expression of adipocyte marker FABP4 was detected on day six by Western Blotting. (G) Morphology of lipid droplets induced by PPAR? expression and hormone treatment (magnification 200X). (H) GLUT4 expression normalized by FABP4 was quantified by real-time PCR in cells treated with PPAR? adenovirus or hormone $\left(n=3,{ }^{*}<<0.05\right)$.

levels, although the importance of C/EBP? phosphorylation requires further investigation.

C/EBP? or C/EBP? is sufficient to induce 3T3-L1 pre-adipocytes to differentiate into mature adipocytes without using inducers [36,37]. Over-expression of C/EBP? alone stimulated differentiation of hBMSCs, as evidenced by FABP4 expression (Figure 4E, 4F). C/EBP? was less effective than C/EBP? as expression of C/EBP? alone did not stimulate differentiation (Figure 5E, 5F). C/EBP? and C/ $\mathrm{EBP}$ ? individually enhanced adipocyte differentiation of hBMSCs dependent on exogenous hormone agent treatment, particularly in the presence of a PPAR? activator (Figure 4E, 4F, 5E, 5F). HBMSCs may lack endogenous
PPAR? ligands; however, this cannot be determined at this time because the results concerning the study of natural PPAR? ligands are indecisive [38].

PPAR? plays pivotal roles in adipocyte differentiation as it induces adipogenesis in cultured mouse fibroblasts [14]. With the use of high affinity, selective PPAR? agonists, PPAR? activation stimulates 3T3-F442A cells to develop into mature fat cells with a phenotype that includes morphological changes, lipid accumulation, and the acquisition of insulin sensitivity [39]. In addition, ectopic expression of PPAR? in hBMSCs initiates adipocyte differentiation. However, these cells were immature adipocytes, as demonstrated by morphological observations 
and the expression of some adipocyte-specific genes (Figure 6G, 6H). In humans, PPAR? functions to regulate a part of genes required for adipocyte maturation, as demonstrated by its ability to induce FABP4 but not GLUT4 expression (Figure $6 \mathrm{H}$ ). In addition, PPAR? could play a role in cytoskeletal alterations associated with the morphological changes during differentiation, as the cells rounded up when PPAR? was over-expressed and elongated when expression of PPAR? was knocked down.

\section{Conclusions}

This study demonstrates that the characteristics of hBMSCs during adipogenic differentiation are different from those of mouse cells. HBMSCs do not undergo mitotic clonal expansion during adipocyte differentiation. $\mathrm{C} /$ EBP?, C/EBP?, and PPAR? are all required but not sufficient for adipocyte differentiation from hBMSCs. The ability of the transcription factors to stimulate adipocyte differentiation differed between human and murine cells. Further studies concerning on how $\mathrm{C} / \mathrm{EBP}$ ?, $\mathrm{C} / \mathrm{EBP}$ ? and PPAR? regulating human adipocyte differentiation could help to elucidate the molecular mechanism of adipocyte differentiation from human stem cells, help to elucidate the mechanisms underlying human obesity and identify therapeutic targets.

\section{Methods}

\section{Donor information}

Bone marrow was obtained from the iliums of patients undergoing iliac crest bone grafts following informed consent. Five samples were obtained from male patients between the ages of 25 and 55 years who did not suffer from obesity and/or diabetes. The sample collection procedure and related research work was approved by the ethics committee of Institutes of Biomedical Sciences, Fudan University. Results were reproducible between donors, and the data presented in the results section were from a 32-year-old male donor.

\section{Isolation and adipogenic differentiation of hBMSCs}

HBMSCs were isolated by density gradient centrifugation with Ficoll-Paque (GE Healthcare) and plastic adherence and grown in DMEM (low glucose, Invitrogen) containing $10 \%$ fetal bovine serum and $1 \%$ antibiotics; cells from passages 3-5 were used experimentally. A published protocol was followed to induce adipogenic differentiation of hBMSCs [26]. HBMSCs were cultured at a density of $5000 \sim 6000$ cells $/ \mathrm{cm}^{2}$. After reaching confluence, hBMSCs were cultured for one more week and induced in adipogenic medium containing $0.5 \mathrm{mM}$ isobutylmethylxanthine (Sigma-Aldrich), 1 ?M dexamethasone (Sigma-Aldrich), 10 ?M insulin (Roche), 100 ?M indomethacin (Sigma-Aldrich) for three days and maintained in medium with 10 ?M insulin for one day. The treatment was repeated two or three times, after which the cells were maintained in DMEM with 10 ?M insulin until day 21 and subjected to oil red $O$ staining to detect cytoplasmic triglyceride.

\section{Oil red $O$ staining}

Cells were washed three times with PBS and then fixed for $2 \mathrm{~min}$ with $3.7 \%$ formaldehyde. Oil red O (0.5\% in isopropanol) was diluted with water (3:2) filtered through a 0.45 ? $\mathrm{m}$ filter and incubated with the fixed cells for $1 \mathrm{~h}$ at room temperature. Cells were washed with water and the stained fat droplets in the cells were visualized by light microscopy and photographed. The percentage of differentiated cells was determined by counting cells based on oil red staining in the lipid vacuoles and 4',6'-diamidino2-phenylindole staining of DNA.

\section{Western blotting}

At various time points cells were washed with cold PBS (pH 7.4) and lysed with lysis buffer (2\% SDS, $60 \mathrm{mM}$ Tris$\mathrm{Cl}, \mathrm{pH}$ 6.8). The lysates were heated to $100^{\circ} \mathrm{C}$ for $10 \mathrm{~min}$ and clarified by centrifugation; equal amounts of protein were separated by SDS-PAGE. Proteins were transferred to poly(vinylidene difluoride) membranes and immunoblotted with antibodies to FABP4(422/aP2), C/EBP?, C/ EBP?, and PPAR? [antibodies to 422/aP2, C/EBP? and C/ EBP? were provided by Dr. M Daniel Lane (Johns Hopkins University School of Medicine, Baltimore) and the antibody to PPAR? was purchased from Cell Signalling Technology ].

\section{Cell cycle analysis by propidium iodide staining and flow cytometry}

Cells were trypsinized, washed with PBS and fixed with $2 \%(\mathrm{wt} / \mathrm{vol})$ paraformaldehyde in PBS. They were treated with $0.5 \mathrm{mg} / \mathrm{ml} \mathrm{RNase}$ A for $1 \mathrm{~h}$ at room temperature and incubated with $0.1 \mathrm{mg} / \mathrm{ml}$ propidium iodide (Sigma) for $45 \mathrm{~min}$ at $37^{\circ} \mathrm{C}$. DNA content was determined by flow cytometry (Bio-Rad).

\section{BrdU labelling and immunofluorescence microscopy}

BrdU labeling of hBMSCs and 3T3-L1 cells (kindly provided by Dr. M Daniel Lane, Johns Hopkins University School of Medicine, Baltimore) was performed following the procedure published by Tang [8] with modifications. Cells were plated on to cover-slips and maintained in DMEM containing 10\% FBS for several days after confluence and induced to differentiate. Regarding the growth kinetics differennce (hBMSCs have a longer G0/G1 phase than 3T3-L1, the entry of hBMSCs into $S$ phase is $\sim 20 \mathrm{~h}$ at passage 3 [40]), BrdU for 3T3-L1, BrdU (10 ?g/ml) was added at $18 \mathrm{~h}$ after induction (during $\mathrm{S}$ phase[8]) until 48 $\mathrm{h}$ and then shifted to maintain medium (with insulin only); for hBMSCs, BrdU was added at $24 \mathrm{~h}$ until $72 \mathrm{~h}$. After differentiation, the cover-slips were fixed in $70 \%$ 
ethanol for $30 \mathrm{~min}$ followed by $100 \%$ methanol for $10 \mathrm{~min}$ at room temperature. The fixed cells were treated for 30 min with $1.5 \mathrm{M} \mathrm{HCl}$, blocked with $0.5 \%$ Tween 20 in PBS with $10 \%$ FBS for $5 \mathrm{~min}$, incubated with anti-BrdU (1:100, Sigma) or anti-perilipin (1:50, Santa Cruz) primary antibodies in the same buffer overnight, and incubated with FITC/TRITC-conjugated secondary antibodies for 1-2 $h$. Nuclei were counterstained with 4 ,6-diamidino-2-phenylindole (DAPI). Images were taken on a confocal microscope.

\section{Adenoviral expression vectors and infection} The adenoviral expression vectors $\mathrm{pAd} / \mathrm{CMV} / \mathrm{V} 5$-DEST (Invitrogen) encoding human C/EBP?, C/EBP?, PPAR? and Lac $\mathrm{Z}$ (control) were constructed according to the manufacturer's protocols. shRNAs for C/EBP?, PPAR? and $\mathrm{Lac} \mathrm{Z}$ were cloned into pBlock-it (Invitrogen). The sequences of the shRNAs were as follows: C/EBP?, CACCAGGAGGATGAAGCCAAGCAGCTCGAAAGCTGCTTGGCTTCATCCTCCT. PPAR?, CACCGGGTGAAACTCTGGGAGATTCCGAAGAATCTCCCAGAGTTTCACCC. Confluent hBMSCs were infected with the adenovirus at MOI (multiplicity of infection) of 10 for $4 \mathrm{~h}$; the expression of human C/EBP?, C/EBP?, PPAR? was assessed by real-time PCR at $24 \mathrm{~h}$ or by immunoblotting with antibodies against human $\mathrm{C} /$ EBP?, C/EBP?, PPAR? and FLAG at 48 h. For adipocyte differentiation, various combinations of inducers were added to the infected cells for three days. Oil red $\mathrm{O}$ staining was used to demonstrate fat lipid accumulation on day eight and western blotting was used to demonstrate FABP4 (422/aP2 in mouse) expression on day four.

\section{RNAi of C/EBP? with siRNA}

SiRNA oligonucleotides specific for C/EBP? mRNA (5'CCCUGCGGAACUUGUUCAAGCAGCU-3') were synthesized by Invitrogen. The silencing effect was verified by real-time PCR for C/EBP? expression. HBMSCs in 60 $\mathrm{mm}$ dishes at $60-70 \%$ confluence were transfected with Negative and C/EBP? siRNA oligonucleotides by using Lipofectamine RNAiMAX (Invitrogen). After $24 \mathrm{~h}$ the cells were trypsynized and plated into $35 \mathrm{~mm}$ dishes in order to reach confluence immediately. After a further 24 $\mathrm{h}$ they were induced to differentiate by three cycles of treatment, and subjected to oil red O staining at day 14.

\section{Real-time quantitative PCR}

Real-time quantitative PCRs were performed with $2 \times$ PCR Master Mix (Power SYBR Green, ABI) on a Bio-Rad Q5 instrument (Bio-Rad). The threshold cycles (Ct) for the target genes and the $18 \mathrm{~S}$ rRNA control signals were determined in triplicate experiments, and the relative RNA quantity was calculated using the comparative $\mathrm{Ct}$ method. Primers were as follows:
18S rRNA: Forward 5'-CGGCTACCACATCCAAGGAA-3', Reverse 5'-GCTGGAATTACCGCGGCT-3'. C/EBP?: Forward 5'-GCAAGAGCCGCGACAAG-3', Reverse 5'-GGCTCGGGCAGCTGCTT-3'. C/EBP?: Forward 5'-AAGAAGTCGGTGGACAAGAACAG-3', Reverse 5'-TGCGCACCGCGATGT-3'. PPAR?: Forward 5'-GATACACTGTCTGCAAACATATCACAA-3', Reverse 5'-CCACGGAGCTGATCCCAA-3'. FABP4: Forward 5'-GCTTTGCCACCAGGAAAGTG-3', Reverse 5'-ATGGACGCATTCCACCACCA-3'. GLUT4: Forward 5'-GCCGGACGTTTGACCAGAT-3', Reverse 5'-TGGGTTTCACCTCCTGCTCTA-3'.

\section{Statistics}

Data were expressed as the mean \pm SD of three separate experiments performed in duplicate. Student's $t$-test was used for comparison of results in Figure 4C, Figure 5C and Figure $6 \mathrm{C} \& 6 \mathrm{H}$.

\begin{abstract}
Authors' contributions
SWQ designed the study, carried out the molecular genetics and cell biological studies, performed the statistical analysis, and drafted the manuscript. XL participated in the design of the study and the sequence alignment. YYZ participated in the construction of the vectors. $\mathrm{HYH}$ participated in the statistical analysis. YL participated in the cell biological studies. XS performed the confocal scan. QQT conceived the study and participated in its design and coordination, and helped to draft the manuscript. All authors read and approved the final manuscript.
\end{abstract}

\section{Acknowledgements}

This research is supported by National Key Basic Research Project Grant 2006CB943704, National Natural Science Foundation for Distinguished Scholars Grant 30625015, National Natural Science Foundation Grant 30700121 and 30870510, Program for Outstanding Medical Academic Leader Grant BLJ06032, Shanghai Key Science and Technology Research Project 08dj1 400603, Program for New Century Excellent Talents in University NCET-08-0130 and Shanghai Rising Star Program 08QA14012. The Department is supported by Shanghai Leading Academic Discipline Project, Project Number: B110.

\section{Author Details}

1Institute of Stem Cell Research and Regenerative Medicine, Institutes of Biomedical Sciences, Fudan University, Shanghai 200032, PR China and ${ }^{2}$ The Key Laboratory of Molecular Medicine, the Ministry of Education, Department of Biochemistry and Molecular Biology, Shanghai Medical College, Fudan University, Shanghai 200032, PR China

Received: 31 December 2009 Accepted: 7 May 2010 Published: 7 May 2010

\section{References}

1. Hirsch J, Batchelor B: Adipose tissue cellularity in human obesity. Clin Endocrinol Metab 1976, 5:299-311.

2. Shepherd PR, Gnudi L, Tozzo E, Yang H, Leach F, Kahn BB: Adipose cell hyperplasia and enhanced glucose disposal in transgenic mice overexpressing GLUT4 selectively in adipose tissue. J Biol Chem 1993, 268:22243-22246

3. Yu ZK, Wright JT, Hausman GJ: Preadipocyte recruitment in stromal vascular cultures after depletion of committed preadipocytes by immunocytotoxicity. Obesity Res 1997, 5:9-15.

4. Crisan M, Yap S, Casteilla L, Chen CW, Corselli M, Park TS, Andriolo G, Sun B, Zheng B, Zhang L, Norotte C, Teng PN, Traas J, Schugar R, Deasy BM, Badylak S, Buhring HJ, Giacobino JP, Lazzari L, Huard J, Pe'ault B: A Perivascular Origin for Mesenchymal Stem Cells in Multiple Human Organs. Cell Stem Cell 2008, 3:301-313.

5. Crossno JT Jr, Majka SM, Grazia T, Gill RG, Klemm DJ: Rosiglitazone promotes development of a novel adipocyte population from bone 
marrow-derived circulating progenitor cells. J Clin Invest 2006 116:3220-8.

6. Green $\mathrm{H}$, Meuth M: An established pre-adipose cell line and its differentiation in culture. Cell 1974, 3:127-33.

7. Green $\mathrm{H}$, Kehinde O: Spontaneous heritable changes leading to increased adipose conversion in 3T3 cells. Cell 1976, 7:105-13.

8. Tang QQ, Otto TC, Lane MD: Mitotic clonal expansion: a synchronous process required for adipogenesis. Proc Natl Acad Sci USA 2003, 100:44-49.

9. MacDougald OA, Lane MD: Transcriptional regulation of gene expression during adipocyte differentiation. Annu Rev Biochem 1995, 64:345-373.

10. Tang QQ, Grønborg M, Huang H, Kim JW, Otto TC, Pandey A, Lane MD: Sequential phosphorylation of CCAAT enhancer-binding protein beta by MAPK and glycogen synthase kinase 3 beta is required for adipogenesis. Proc Natl Acad Sci USA 2005, 102:9766-71.

11. Li X, Kim JW, Grønborg M, Urlaub H, Lane MD, Tang QQ: Role of cdk2 in the sequential phosphorylation/activation of C/EBPbeta during adipocyte differentiation. Proc Natl Acad Sci USA 2007, 104:11597-11602.

12. Darlington GJ, Ross SE, MacDougald OA: The role of C/EBP genes in adipocyte differentiation. J Biol Chem 1998, 273:30057-60.

13. Freytag SO, Paielli DL, Gilbert JD: Ectopic expression of the CCAAT/ enhancer binding protein alpha promotes the adipogenic program in a variety of mouse fibroblastic cells. Genes Dev 1994, 8:1654-1663.

14. Tontonoz P, Hu E, Spiegelman BM: Stimulation of adipogenesis in fibroblasts by PPAR?2, a lipid-activated transcription factor. Cell 1994 79:1147-1156

15. Wu Z, Rosen E, Brun R, Hauser S, Adelmant G, Troy A, McKeon C, Darlington G, Spiegelman B: Cross-regulation of C/EBP? and PPAR? controls the transcriptional pathway of adipogenesis and insulin sensitivity. Mol Cell 1999, 3:151-158.

16. El-Jack AK, Hamm JK, Pilch PF, Farmer SR: Reconstitution of insulinsensitive glucose transport in fibroblasts requires expression of both PPAR? and C/EBP?. J Biol Chem 1999, 274:7946-7951.

17. Campagnoli C, Roberts I, Kumar S, Bennett P, Bellantuono I, Fisk N: Identification of mesenchymal stem/progenitor cells in human firsttrimester fetal blood, liver, and bone marrow. Blood 2001 98:2396-2402

18. In't Anker PS, Scherjon SA, Kleijburg-van der Keur C, Noort WA, Claas FH, Willemze R, Fibbe WE, Kanhai HH: Amniotic fluid as a novel source of mesenchymal stem cells for therapeutic transplantation. Blood 2003, 102:1548-1549.

19. Erices $A$, Conget $P$, Minguell JJ: Mesenchymal progenitor cells in human umbilical cord blood. Br J Haematol 2000, 109:235-242.

20. De Bari C, Dell'Accio F, Tylzanowski P, Luyten FP: Multipotent mesenchymal stem cells from adult human synovial membrane. Arthritis Rheum 2001, 44:1928-1942.

21. Kuznetsov SA, Mankani MH, Gronthos S, Satomura K, Bianco P, Robey PG Circulating skeletal stem cells. J Cell Biol 2001, 153:1133-1140.

22. Tondreau T, Meuleman N, Delforge A, Dejeneffe M, Leroy R, Massy M, Mortier C, Bron D, Lagneaux L: Mesenchymal stem cells derived from CD133-positive cells in mobilized peripheral blood and cord blood: proliferation, Oct4 expression, and plasticity. Stem Cells 2005, 23:1105-1112.

23. Dominici M, Le Blanc K, Mueller I, Slaper-Cortenbach I, Marini F, Krause D, Deans R, Keating A, Prockop Dj, Horwitz E: Minimal criteria for defining multipotent mesenchymal stromal cells. The International Society for Cellular Therapy position statement. Cytotherapy 2006, 8:315-7.

24. Bruder SP, Jaiswal N, Haynesworth SE: Growth kinetics, self-renewal, and the osteogenic potential of purified human mesenchymal stem cells during extensive subcultivation and following cryopreservation. J Cell Biochem 1997, 64:278-94.

25. Lehmann JM, Lenhard JM, Oliver BB, Ringold GM, Kliewer SA: Peroxisome proliferator-activated receptors alpha and gamma are activated by indomethacin and other non-steroidal anti-inflammatory drugs. J Biol Chem 1997, 272:3406-10.

26. Pittenger MF, Mackay AM, Beck SC, Jaiswal RK, Douglas R, Mosca JD, Moorman MA, Simonetti DW, Craig S, Marshak DR: Multilineage potential of adult human mesenchymal stem cells. Science 1999, 284:143-7.

27. Pairault J, Green $\mathrm{H}$ : A study of the adipose conversion of suspended $3 \mathrm{~T} 3$ cells by using glycerophosphate dehydrogenase as differentiation marker. Proc Natl Acad Sci USA 1979, 76:5138-5142.
28. Huang HY, Song TJ, Li X, Hu LL, He Q, Liu M, Lane MD, Tang QQ: BMP signaling pathway is required for commitment of $\mathrm{C} 3 \mathrm{H} 10 \mathrm{~T} 1 / 2$ pluripotent stem cells to the adipocyte lineage. Proc Natl Acad Sci USA 2009, 106:12670-12675.

29. Tang QQ, Otto TC, Lane MD: CCAAT/enhancer-binding protein beta is required for mitotic clonal expansion during adipogenesis. Proc Natl Acad Sci USA 2003, 100:850-5.

30. Entenmann $\mathrm{G}$, Hauner $\mathrm{H}$ : Relationship between replication and differentiation in cultured human adipocyte precursor cells. Am Physiol 1996, 270(4 Pt 1):C1011-6.

31. Zuk PA, Zhu M, Ashijian P, De Ugarte DA, Huang II Mizuno H, Alfonso ZC Fraser JK, Benhaim P, Hedrick MH: Human Adipose Tissue is a Source of Multipotent Stem Cells. Mol Biol Cell 2002, 13:4279-4295.

32. Rodriguez AM, Elabd C, Delteil F, Astier J, Vernochet C, Saint-Marc P, Guesnet J, Guezennec A, Amri EZ, Dani C, Ailhaud G: Adipocyte differentiation of multipotent cells established from human adipose tissue. Biochem Biophys Res Commun 2004, 315:255-63.

33. Vasseur-Cognet M, Lane MD: Trans-acting factors involved in adipogenic differentiation. Curr Opin Genet Dev 1993, 3:238-45.

34. Tang QQ Lane MD: Activation and centromeric localization of CCAAT/ ehnancer binding proteins during the mitotic clonal expansion of adipocyte differentiation. Genes Dev 1999, 13:2231-2241.

35. Wu Z, Xie Y, Bucher NL, Farmer SR: Conditional ectopic expression of C/ EBP beta in NIH-3T3 cells induces PPAR gamma and stimulates adipogenesis. Genes Dev 1995, 9:2350-63.

36. Hamm JK, Park BH, Farmer SR: A role for C/EBPbeta in regulating peroxisome proliferator-activated receptor gamma activity during adipogenesis in 3T3-L1 preadipocytes. J Biol Chem 2001, 276:4-71. 1846

37. Lin FT, Lane MD: CCAAT/enhancer binding protein alpha is sufficient to initiate the 3T3-L1 adipocyte differentiation program. Proc Nat/ Acad Sci USA 1994, 91:8757-61.

38. Kim JB, Wright HM, Wright M, Spiegelman BM: ADD1/SREBP1 activates PPARgamma through the production of endogenous ligand. Proc Natl Acad Sci USA 1998, 95:4333-7.

39. Sandouk T, Reda D, Hofmann C: Antidiabetic agent pioglitazone enhances adipocyte differentiation of 3T3-F442A cells. Am J Physiol 1993, 264(6 Pt 1):C1600-8.

40. Zhang Y, Li CD, Jiang XX: Comparison of mesenchymal stem cells from human placenta and bone marrow. Chinese Medical Journal 2004, 117:882-887.

doi: 10.1186/1471-213X-10-47

Cite this article as: Qian et al., Characterization of adipocyte differentiation from human mesenchymal stem cells in bone marrow BMC Developmental Biology 2010, 10:47

\section{Submit your next manuscript to BioMed Centra and take full advantage of:}

- Convenient online submission

- Thorough peer review

- No space constraints or color figure charges

- Immediate publication on acceptance

- Inclusion in PubMed, CAS, Scopus and Google Scholar

- Research which is freely available for redistribution 